\title{
Otras formas de defender el territorio: la revitalización cultural e identitaria del pueblo cochimí de Baja California
}

\section{Other Forms of Territorial Defense: \\ Cultural and Identity Revitalization of the Cochimí from the Baja California Peninsula}

\author{
B. Alejandra Velasco Pegueros \\ iD https://orcid.org/0000-0002-3030-2240 \\ Universidad Autónoma Metropolitana -Xochimilco, México \\ ale_town @hotmail.com
}

\section{Resumen:}

Este artículo ofrece un acercamiento a las problemáticas territoriales de los pueblos nativos de Baja California, en específico de las y los descendientes del pueblo cochimí del desierto central de la península quienes, a raíz de la pérdida de sus derechos agrarios, y a pesar de haber sido considerados extintos durante mucho tiempo, se organizaron en un proceso de revitalización cultural e identitaria para luchar por su territorio. A lo largo de estas páginas intento dar cuenta de cómo a pesar de los cambios culturales y la desterritorialización, la pertenencia territorial puede volverse un sólido emblema para la reconfiguración de la identidad étnica y ser un elemento importante en la creación de nuevas formas de resistencia en momentos de confrontación o disputa por el territorio.

Palabras clave: resistencia cultural, Aridoamérica, Yumano-cochimí, pertenencia territorial, reivindicación étnica.

Abstract:

This paper addresses territorial issues faced by the native peoples of Baja California, specifically the descendants of the Cochimí people from the peninsula's central desert. Having lost their agrarian rights and despite having for a long time been considered extinct, the Cochimí organized a process of cultural and identity revitalization in order to fight for their territory. This paper demonstrates how in spite of cultural changes and deterritorialization, territorial belonging can become a solid symbol to reconfigure ethnic identity and become an important element in the creation of new forms of resistance in moments of territorial confrontation or dispute.

Key Words: cultural resistance, Aridoamerica, Yumano-Cochimí, territorial belonging, ethnic assertion.

1 Una versión preliminar de este trabajo fue presentada como ponencia en el IV Seminario Democracia, cultura política y ciudadanía: Respuestas comunitarias para la exigibilidad de derechos y defensa del territorio en tiempos del neoliberalismo, celebrado en la Universidad Veracruzana Intercultural, sede Totonacapan, en Espinal, Veracruz, del 15 al 17 de octubre de 2018. 


\section{Introducción}

No obstante los discursos esencialistas que hasta hace poco pregonaban su extinción, los pueblos nativos de Baja California ${ }^{2}$ han resistido, desde sus especificidades geográficas, históricas y culturales, a los cambios sociales impuestos por los sistemas dominantes de cada época, así como a las invasiones e injusticias en sus comunidades de origen y han luchado, desde hace algunos años, por su derecho a existir ante el doble reto que viven en la actualidad: el de permanecer en lo poco que les queda de sus territorios ancestrales, y la persistencia de sus lenguas maternas, de sus saberes y sus prácticas indígenas. Con el fin de reflexionar al respecto, este artículo brinda un panorama general del complejo cultural yumano-cochimí ${ }^{3}$ y sus problemáticas territoriales profundizando en la resistencia del pueblo cochimí, un grupo que durante mucho tiempo fue considerado extinto debido a la asimilación que, se argumentaba, habían vivido a partir del contacto con el sistema misional. Sin embargo, después de un largo proceso de transformación cultural, descendientes cochimíes del desierto central bajacaliforniano emergieron a través de su organización en la asociación Milapá para exigir su reconocimiento como un pueblo vivo, a la vez que pedían apoyo para la recuperación de su territorio y de los derechos agrarios de los que injustamente fueron depurados, poniendo a debate el exterminio de los pueblos de la península y, también, la cuestión étnica en el noroeste del país.

En las siguientes páginas se exponen algunos elementos para enriquecer este debate y a partir de las voces y experiencias del pueblo cochimí se profundiza en la relevancia del territorio en su proceso de revitalización cultural e identitaria a la par de las reflexiones sobre la configuración de nuevas formas de resistencia cultural en los pueblos de la Aridoamérica.

2 Tanto los pueblos yumanos del norte de la península (kumiay, pai pai, kiliwa y cucapá) como el cochimí del desierto central se autodenominan como «nativos» para diferenciarse de los pueblos originarios que han migrado a esta región, sobre todo mixtecos, purépechas y triquis. 3 Retomo el término «complejo cultural yumano» que utiliza Everardo Garduño (2011) para referirse a los cuatro pueblos del norte de la península, pero agrego el cochimí para incluir a este pueblo dentro del conglomerado pues si bien son parte de una misma familia etnolingüística y sus lenguas proceden de un origen común, son dos ramas distintasy son grupos con historicidadesyespecificidades. 


\section{Los pueblos originarios de Baja California: una mirada panorámica a su devenir histórico}

Hasta ahora los estudios arqueológicos realizados en Baja California coinciden al calcular que el arribo de las y los primeros pobladores a la península ocurrió hace aproximadamente 13 mil años, después de que el descongelamiento del hemisferio norte provocara el desplazamiento de diversos grupos a otros territorios del sur (Garduño, 1994):

el éxodo de estas culturas del desierto del Colorado y Mójave hacia Baja California, obedeció a distintas causas y se presentó en distintos momentos, pero en cuanto a las primeras oleadas, todo parece apuntar que la causa principal fue una intensa sequía que sobrevino al término de la última glaciación. En este evento ocurrieron cambios atmosféricos radicales, como la desaparición de los lagos del pleistoceno, la prevalencia de un clima mucho más árido y la extinción de numerosas plantas y animales que constituían la dieta de estas culturas; por esta razón, se puede decir que los primeros inmigrantes de Baja California llegaron en busca de alimento a sus litorales, a sus riachuelos y a sus diferentes hábitats (Álvarez en Garduño, 1994:23).

Este hecho histórico y ambiental descrito por Anita Álvarez corresponde al periodo denominado Paleoindígena, del cual surgieron dos complejos culturales: el grupo Clovis, del 13000 al 11000 antes de nuestra era, y el complejo San Dieguito, que habitaron este espacio entre el 11000 y 7000 a. p. ${ }^{4}$ Los cambios en el clima, así como la alimentación que podían obtener de los territorios, agudizaron su movilidad, llevando en el periodo denominado Arcaico, al desarrollo del complejo Amargosa, que habitó las regiones interiores del norte de la península, y el La Jollano, entre las costas del Pacífico y del Golfo de California (Morales, 2016). Por su parte, en el desierto central y el sur de la península también se conformaron algunos complejos culturales. Según Massey (en Uriarte, 2013), el poblamiento de esta zona devino de los continuos reacomodos realizados por pequeños grupos de cazadores, recolectores y pescadores quienes durante las migraciones descendieron por la zona e incorporaron o eliminaron a los anteriores. Para este arqueólogo, los complejos que habitaron la península a partir del

\footnotetext{
${ }^{4}$ Antes del presente (a. p.) es una escala de tiempo utilizada en la arqueología para especificar cuándo ocurrió un evento en el pasado.
} 
desierto central fueron la cultura de Las Palmas, antecedente de los grupos guaycuras y cuyos integrantes habitaron sobre todo en el sur, y la cultura Comondú, «raíz de la población cochimí». Así, para Massey, durante la Prehistoria tardía existieron dos grupos lingüísticos distintos en esta parte del territorio peninsular: el guaycura y el yumano peninsular o cochimín (Massey en Uriarte, 2013) aunque para Laylander la conformación de estos complejos comenzaría en el periodo Arcaico, siendo los hombres y las mujeres de este tiempo los antepasados de la familia etnolingüística yumana-cochimí (Laylander en Morales, 2016).

Después de las migraciones y reacomodos por el territorio peninsular, el asentamiento, el desarrollo cultural y la diferenciación lingüística de los actuales grupos indígenas de la Baja California sucedieron aproximadamente en el 2500 a. C dando como resultado la configuración de los grupos cochimíes en el desierto central, de guaycuras y pericúes en el sur de la península y, en el norte, de los pueblos kumiay, pai pai, cucapá y kiliwa, denominados desde la antropología como yumanos ${ }^{6}$ (Garduño, 1994).

Por su parte, descendientes del grupo hokano-sioux ${ }^{7}$ ya como sociedades nómadas, cazadoras-recolectoras ${ }^{8}$ y en algunos casos pescadoras, crearon sistemas culturales con características muy distintas a las de los grupos de otras latitudes, acordes también a las condiciones de vida que el clima y la tierra de esta región les permitieron (véase mapa 1).

5 Por alguna razón Massey (1949) incluyó a los pericúes dentro de la familia de los guaycuras, pues ambos grupos ocuparon el sur de la península, aunque en diferentes latitudes. Otros autores que abordo más adelante hablan de tres grupos lingüísticos: pericúes, guaycuras y cochimíes.

6 Si bien las clasificaciones como yumanos, cochimíes o yumanos peninsulares fueron categorías impuestas por «los estudiosos», la finalidad de su utilización en este apartado es para referirme a los pueblos de Baja California de manera general.

7 Familia etnolingüística que agrupa a una variedad de lenguas habladas por los pueblos originarios de lo que actualmente conocemos como Norteamérica (Estados Unidos y Canadá).

8 En su libro Los Cazadores (1984), Service aborda un detallado estudio sobre las sociedades cazadoras-recolectoras e indica que estas se caracterizaban por una integración familiar más allá del parentesco o del territorio. Su organización se basaba en la familia y no existía como tal una especialización económica, política o religiosa, ya que las divisiones se fundaban en diferencias de edad o sexo. No tenían escritura y su numeración era limitada, solo llegaba hasta cinco, por lo que para referirse a una cantidad mayor utilizaban «mucho o muchísimo»; los regía el calendario lunar y cuando requerían abarcar periodos mayores se basaban en las estaciones del año relacionadas con los cambios que observaban en la naturaleza (Service en Uriarte, 2013:40, 41). 
Mapa 1.- Familia etnolingüística yumana-cochimí

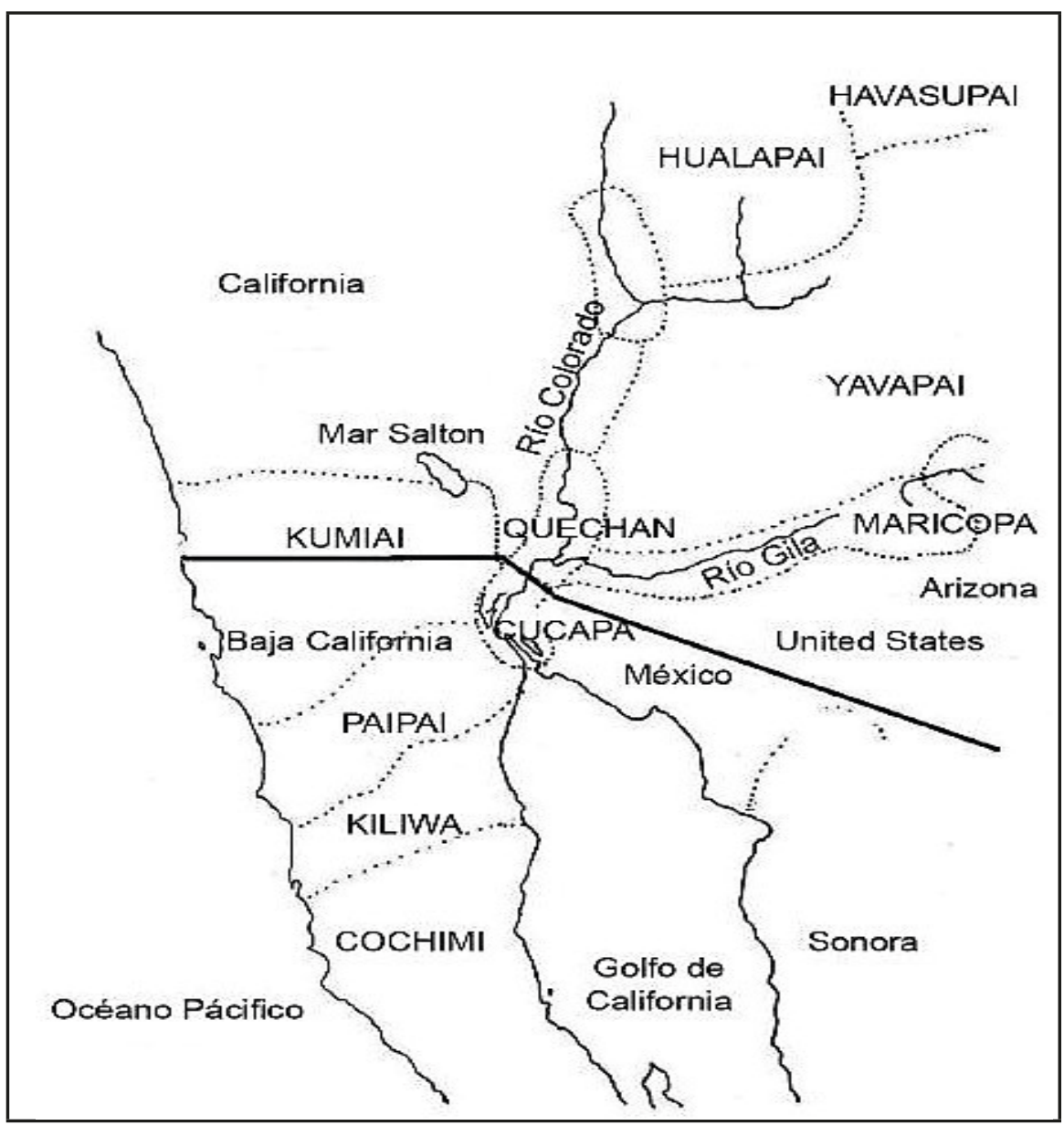

Fuente: Garduño, 2010.

Fue la árida geografía lo que les condujo a una vida seminómada dependiente de los ciclos estacionales y del alimento que pudieran obtener según cada temporada, por lo que, a diferencia de los pueblos mesoamericanos que hicieron de la agricultura su principal modo de vida conformando una forma de organización social y política más colectiva, los pueblos del norte se caracterizaron por una movilidad constante por el territorio y aunque existen algunas evidencias de que el pueblo cucapá sí sembraba, la agricultura no fue una actividad extendida en los demás grupos yumano-cochimíes. La organización social de estos pueblos se basaba en el shumul, un tipo de «unidad social ampliada» que reunía a individuos que reconocían su ascendencia a través de la línea paterna la cual regía 
la organización de estos grupos tanto en la patrilocalidad como en la patrilinealidad (Michelsen, 1991), aunque no era precisamente una agrupación lingüística uniforme y unida «sino comunidades que tenían derecho a cierto territorio, vía parentesco y que [lo] defendían si era necesario» (Laylander en Morales, 2016:73) en donde cada banda tenía su propio líder y solo los varones podían fungir como chamanes. Además de ser la base de su organización para obtener los alimentos necesarios, ${ }^{9}$ esta estructura social configuró tareas para cada género, pues mientras las mujeres se enfocaban en la recolección de frutos y leña para mantener prendido el fuego para sus familias, en el cuidado de hijos, hijas y de personas mayores -aunque también cazaban algunos animales pequeños (Meigs, 1939)los hombres solían dedicarse casi exclusivamente a cazar y pescar aunque también eran los responsables de recolectar algunos frutos como la pitahaya.

Empero, para el siglo XVIII las características de estos grupos cazadores-recolectores se reconfiguraron a partir de un complejo proceso de cambio sociocultural implantado por el sistema misional y la colonización española, lo cual marcó un importante momento en su devenir histórico, pues de ser nómadas, vivir en shumules y dedicarse a la recolección estacional, pasaron a un sistema de vida sedentario alrededor de las misiones en donde aprendieron nuevas prácticas como la siembra en huertas y la cría de ganado, a la vez que se rebelaban contra un sistema que implacablemente intentaba imponerse «con la espada y con la cruz». ${ }^{10}$ Años más adelante, al consumarse la Independencia de México y sobre todo después del movimiento revolucionario de 1910, sobrevino un momento de cambio pues a pesar de las especificidades culturales de estos pueblos - distintas y distantes al proyecto de nación hegemónica -las políticas integracionistas llegaron hasta esta región, propiciando una acelerada migración y un estrecho contacto de los grupos nativos con personas de otras culturas del centro y sur

9 La dieta de los antiguos shumules cochimíes se basaba en las condiciones del clima, de la temporada y del acceso que pudieran tener a frutos y plantas de la región, como el palo verde, el zalate, el palo blanco, las semillas de cardón, la biznaga, los datilillos, nopales, tunas, los ciruelos del garambullo y sobre todo el agave o mezcal del que no solo obtenían alimento, sino también fibras para tejer redes y sandalias. Además de la caza de venados, liebres, conejos, borregos cimarrones, berrendos, pumas, coyotes y gatos monteses, algunos grupos migraban hacia la costa para abastecerse del alimento que el mar les brindada en las épocas que este escaseaba tierra adentro.

10 Si bien es cierto que el sistema misional avanzó hasta la Alta California (lo que actualmente se conoce como el norte de Baja California y el sur de California, en EUA) y logró establecer algunas misiones en esta región, es importante mencionar que esta tarea no siempre fue bien recibida entre los pueblos nativos, pues tanto en el sur como en el norte de la península hubo rebeliones en contra del sistema misional. 
de México e incluso del extranjero, ${ }^{11}$ así como la incorporación, modificación y, en algunos casos la no transmisión de ciertos elementos culturales que identificaban y diferenciaban a los grupos de este complejo cultural, como algunos ritos, ceremonias ancestrales y la lengua, ${ }^{12}$ por lo que durante el siglo XX se aseveró que estos grupos vivían un proceso de asimilación que les llevaría a su inminente desaparición.

Fue precisamente esta situación la que detonó el interés por investigar estos pueblos. En un primer momento, algunos geógrafos y antropólogos estadounidenses (Meigs 1939; Massey 1949; Aschmann, 1959; Mathes, 1974) comenzaron a interesarse por estas «culturas del desierto» y desde la historia y la arqueología hicieron interesantes aportes acerca del poblamiento de esta área, de los sistemas culturales de las sociedades cazadoras-recolectoras y su filiación etnolingüística. Fue hasta la década de los setenta cuando investigadoras e investigadores mexicanos (Álvarez, 1975; Mixco, 1978; Ochoa, 1979; Bendímez, 1987, Garduño, 1994) se interesaron por «estudiar» a estos pueblos, sus lenguas, mitos de origen y algunas prácticas culturales como los cantos y las danzas, la producción artesanal, así como los procesos de aculturación que, según su perspectiva, vivían estos grupos.

Sin embargo, y a pesar de las teorías asimilacionistas que hasta hace poco tiempo pregonaban la desaparición de los pueblos originarios de Baja California, en los albores del siglo XXI los pueblos yumano-cochimí iniciaron significativos procesos de revitalización cultural e identitaria a partir de los conflictos territoriales surgidos por el reparto agrario y la conformación de los ejidos en esta región, ya que la dotación de tierras a personas externas a las comunidades nativas así como la adjudicación de sitios sagrados a ejidos mestizos propiciaron la invasión y el despojo de sus territorios ancestrales ocasionando graves problemas en sus comunidades, los cuales se agudizaron con los procesos migratorios y con la in-

11 Debido a la actividad minera y ganadera, a esta zona llegaron personas de nacionalidad inglesa, francesa y árabe desde finales del siglo XIX. Con la política de poblamiento del gobierno de Lázaro Cárdenas, también llegaron de distintos estados del país.

12 De las lenguas indígenas existentes en México, las yumanas se encuentran en grave riesgo de desaparecer. Según datos brindados de manera personal por la lingüista Daniela Leyva, del INAHBC, el grupo con mayor número de hablantes son los pai pai con alrededor de 50, les siguen los kumiay con 35, los cucapá con aproximadamente 10 hablantes y entre los kiliwa solo existen cuatro personas que hablan la lengua. Leyva menciona que el dato es relativo, ya que no se toma en cuenta a los «hablantes pasivos», es decir, personas que entienden la lengua y saben decir algunas frases, pero no la hablan con fluidez. A pesar de ello, es importante considerar que la desaparición de una lengua no significa necesariamente la extinción de un pueblo, ya que la identidad y la autoadscripción son, en la actualidad, referentes de suma relevancia para los pueblos originarios que aunque hayan perdido la lengua siguen asumiéndose como indígenas, como es el caso de los y las cochimíes. 
corporación al trabajo asalariado en empresas o ranchos cercanos, así como con las políticas neoliberales subsecuentes. No obstante, también reordenaron sus respuestas y formas de acción.

\section{Un breve recuento de los daños: problemáticas territoriales en los pueblos yumano-cochimí}

Aunque el reparto agrario quedó asentado como uno de los pilares de la Constitución de 1917, fue tiempo después, hasta finales de los sesenta y durante el mandato de Luis Echeverría Álvarez (de 1970-1976), cuando se llevó a cabo el reparto de tierras en la mayor parte de las comunidades indígenas de Baja California. Para ese entonces ya existía una naturalización de la figura ejidal en todos los grupos rurales sin distinguir peculiaridades socioculturales o geográficas, pues se creía que el ejido era la figura que correspondía a todas las sociedades del campo sin reparar en sus especificidades étnicas y en las características geográficas de zonas distintas a las del centro del país, en donde sí había condiciones más benévolas para la agricultura, así como un milenario sistema agrícola practicado por las culturas mesoamericanas (Kouri, 2015). De esta manera, el ejido como institución para la redistribución de la tierra, fruto del proyecto posrevolucionario, se extendió hasta esta región a pesar de las difíciles condiciones geográficas de los territorios de Baja California. Debido a ello, las tierras que se repartieron fueron para uso ganadero más que para la agricultura, pues el clima de la Aridoamérica prácticamente imposibilitaba el trabajo agrícola como fuente de vida, además con la colonización extranjera la ganadería ya había proliferado en la zona hacía más de cincuenta años. Fue así como todas las comunidades indígenas de los cinco pueblos de Baja California quedaron dentro de alguno de los ejidos que se comenzaron a fundar con el reparto agrario.

De esta manera, el pueblo kumiay con sus asentamientos de origen en San Antonio Nécua, San José de la Zorra y La Huerta, en Ensenada, y en las localidades de Peña Blanca y Juntas de Nejí, en Tecate (véase mapa 2), quedaron dentro de la figura de bienes ejidales, al igual que el pueblo kiliwa de Arroyo de León y el pai pai de San Isidoro y Jamau, en el Valle de Ojos Negros y de la Trinidad, respectivamente. El pueblo cucapá, pescador desde tiempos inmemoriales, quedó enmarcado en el ejido Cucapá Indígena, también con bienes ejidales, al igual 
que las comunidades de Santa Gertrudis y San Borja, al sur de Ensenada -en el desiertocentral-enelejidolndependencia, laprimera,y Nuevo Rosarito, enlasegunda.SoloSantaCatarina, comunidad paipai, seformóconbienescomunales.

Mapa 2.- Comunidades indígenas del norte de Baja California

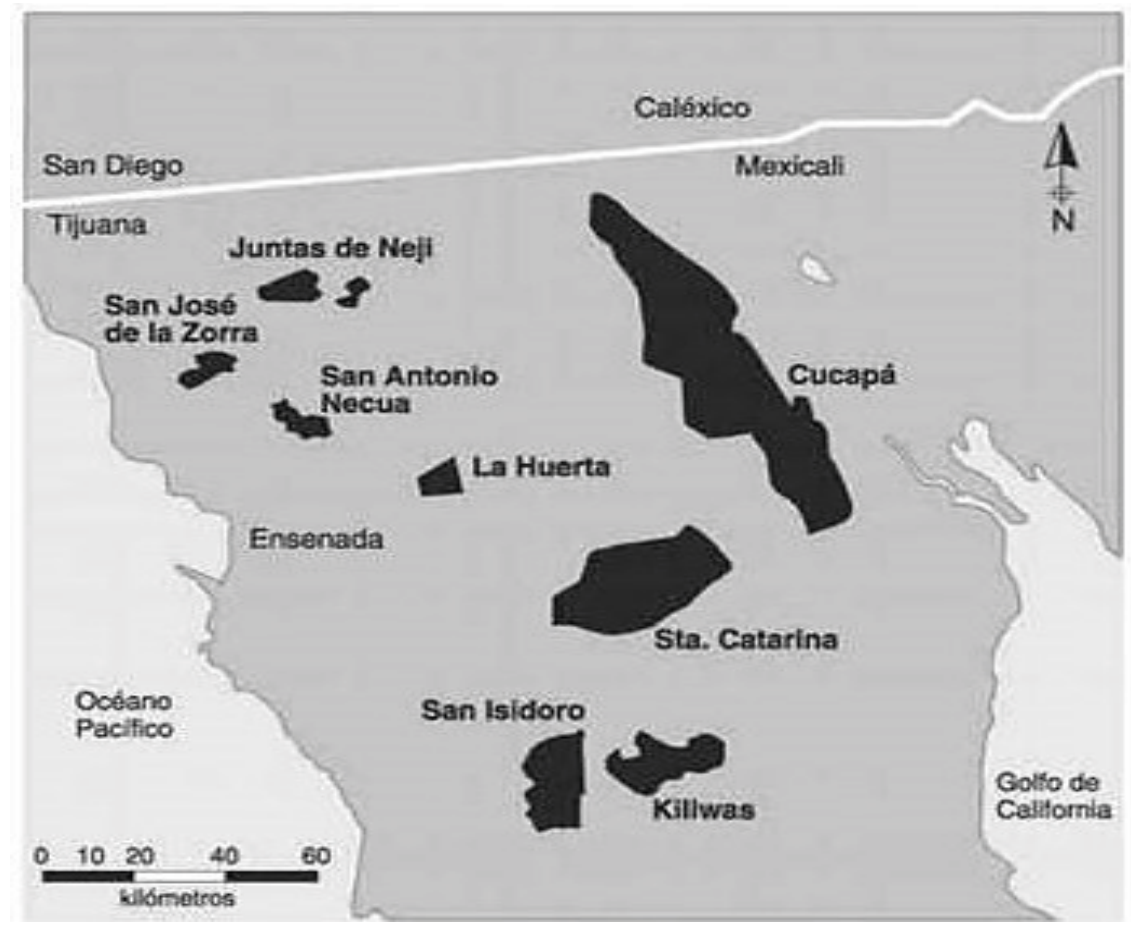

Fuente: Garduño, 2010.

Sin embargo, la poca utilidad de las tierras repartidas y lo poco funcional de la estructura ejidal ${ }^{13}$ provocaron que personas de los pueblos nativos comenzaran a emigrar de sus comunidades de origen en busca de trabajo asalariado a ranchos y localidades cercanas; aunado a ello, la falta de servicios básicos como agua, luz y escuelas fueron factores importantes en la búsqueda de una mejor calidad de vida para sus familias. Con el paso

13 Debido a su forma de organización territorial y social en grupos de familias, más que en sociedades comunitarias, los intentos de colectivizar la tierra resultaron infructuosos generando rencillas entre clanes, sobre todo a partir de la incursión de personas mestizas a los ejidos. Además, la aridez de las tierras y el poco trabajo en ellas no permitió un beneficio real para todas las familias. 
del tiempo y ante la agudización de la migración, personas mestizas con fuerte influencia económica y política en la región comenzaron, gradualmente, con la apropiación, invasión y despojo de territorios indígenas, situación que intensificó los conflictos territoriales relacionados con el acceso y aprovechamiento de recursos naturales como el agua, el aire y la tierra. Frente a este panorama, los problemas que han enfrentado los pueblos de Baja California podrían resumirse en: invasión y despojo, acompañados de injusticia y corrupción. Una muestra de ello se expresa en la comunidad kumiay de San Antonio Nécua, dentro del Valle de Guadalupe, en donde a raíz del crecimiento de la industria vitivinícola las empresas de este ramo comenzaron a crecer y expandirse en el territorio a la vez que avanzaban invadiendo linderos, aguajes y centros ceremoniales de las comunidades. En los últimos años ese conflicto se ha agudizado, en particular con la empresa L.A. Cetto quien no solo ha invadido el territorio ancestral kumiay para el desarrollo de sus plantaciones, sino que cerró el camino vecinal que comunica a San Antonio Nécua con la ciudad de Ensenada. A pesar de que han demandado a la empresa -y esta, a ellos-, de los intentos de diálogo y del proceso jurídico que comenzaron hace años, los problemas no se han solucionado. En otras comunidades kumiay los conflictos han ido más allá de lo territorial, llevando las injusticias hasta la vida cotidiana y personal, como le ocurrió a Aurora Meza Calles, una de las más importantes líderes y relevante pilar en la transmisión de la cultura kumiay de Juntas de Nejí, quien fue encarcelada el 25 de diciembre del 2014 inculpada de abigeato por un vecino del ejido. Dada la falta de pruebas, así como inconsistencias en el proceso, obtuvo la libertad el 6 de marzo del 2015, sin embargo, sus familiares aducen que esta injusta estancia en la cárcel agravó su salud, pues desde entonces comenzó a enfermar cada vez más hasta su deceso en 2017.

Quizá uno de los casos menos conocidos de despojo territorial es el de las y los pai pai de Jamau, quienes se vieron obligados a dejar su territorio ancestral debido a la ambición de una familia mestiza, la familia Loperena, quienes argumentaron que era una zona deshabitada en la que jamás había existido un grupo indígena. Aunque durante mucho tiempo no cesaron los reclamos contra las autoridades correspondientes (incluso llevaron su caso a la ONU, a presidentes de la república, gobernadores y autoridades agrarias) y a pesar de las pruebas sobre su pertenencia al territorio - un estudio antropológico y documentos agrarios-, no han logrado el reconocimiento legal de sus tierras. De esa manera fueron despojados de su comunidad y la mayoría tuvo que irse a vivir a la ciudad de 
Ensenada. Una amenaza similar es la que se cierne sobre descendientes del pequeño pueblo cochimí, quienes fueron depurados de sus derechos agrarios en el ejido Independencia hace más de 30 años debido a la intromisión de una persona externa a la comunidad de Santa Gertrudis que, gracias a su matrimonio con una gertrudina, pudo obtener tierras y comenzó a apoderarse del Comisariado ejidal, cancelando los derechos de una gran mayoría de las familias fundadoras del ejido. ${ }^{14}$

Por su parte, además de sufrir algunas invasiones, el conflicto más grave para el pueblo cucapá se encuentra en otro de sus territorios: el mar, pues a partir de la creación, en 1993, de la Reserva de la Biosfera del Alto Golfo de California y Delta del Río Colorado (en la que sin consulta previa se incluyó la zona en la que tradicionalmente pescan) y de la modificación de las leyes enfocadas a la conservación y aprovechamiento de los recursos marinos, su acceso a la pesca se vio limitado y aunque fueron reconocidos como permisionarios y usuarios comenzaron a ser criminalizados por cualquier actividad de aprovechamiento en su territorio (Bravo, 2018) lo que puso en riesgo su derecho a pescar, la cual es una de las prácticas más importantes no solo en lo económico sino en lo cultural. Esta situación es la razón de su lucha a través de la organización en cooperativas y en donde, por cierto, las mujeres encabezan el proceso.

Aunque según las cifras más del $40 \%$ de la península de Baja California está concesionada para la minería, en las comunidades de los pueblos del norte existe poco conocimiento y resistencia al respecto, incluso contra los parques eólicos establecidos en algunos territorios indígenas como en el ejido Kiliwas, donde la mayoría vendió sus derechos agrarios a mestizos y los que se quedaron arrendaron a la empresa Fuerza Eólica lo poco que conservaban de su territorio, lo cual provocó tensiones y conflictos en la comunidad pues solo quienes cuentan con derechos agrarios recibirieron un porcentaje del pago. Así, sus integrantes se enfrentan no solo al desgaste interno que un proceso como este implica, sino también a un grave problema de pérdida de la lengua pues con solo cuatro hablantes, el kiliwa está en grave riesgo de desaparecer. De igual manera, otro proyecto eólico está dentro del territorio yumano en la comunidad pai pai de Santa Catarina y aunque son bienes comunales en realidad solo las personas con derechos agrarios reciben los beneficios, por lo que la inequitativa distribución de los recursos también ha creado rencillas entre familias de este pueblo.

\footnotetext{
14 Sobre el caso concreto de este pueblo ahondaré en el próximo apartado.
} 
En general, las personas de la comunidad mencionan no tener problemas con la empresa pues no se encuentra como tal dentro de la comunidad sino detrás de los cerros de su territorio ancestral, en el camino que conduce hacia el Golfo de California.

En este sentido, podemos ver que la defensa del territorio en los pueblos de Baja California responde a las invasiones y al despojo por parte de personas externas a las comunidades, más que hacia algún megaproyecto extractivo como la minería, las empresas de energía eólica o alguno relacionado al desarrollo turístico. Empero, con el avance de la minería y otros proyectos que ponen en riesgo el territorio y el patrimonio biocultural de los pueblos yumanos habrá que ver si las relaciones con estas empresas siguen en buenos términos o si la resistencia se bifurca. A pesar de la incertidumbre y del panorama desalentador sobre sus derechos agrarios y territoriales, el complejo cultural yumano-cochimí continúa la reproducción de su cultura en contextos cada vez más complejos y así como vivieron un lento proceso de transformación cultural, ahora reinician un proceso de revitalización que aún tiene mucho por contar. En este proceso, el territorio ha sido un elemento clave en la revitalización cultural e identitaria del pueblo cochimí que, desde su trinchera y sus especificidades, nos muestra otras maneras de vivir y defender el territorio.

\section{De la extinción a la visibilidad: la revitalización cultural e identitaria del pueblo cochimí en defensa del territorio}

Descendientes del complejo Comondú, el pueblo cochimí ha habitado el desierto central de la península de Baja California entre los paralelos 26 y 31, desde lo que en la actualidad conocemos como Loreto hasta San Felipe, en la costa del Golfo de California (véase mapa 3). Sin embargo, con la llegada del colonialismo español, su organización social y sus prácticas culturales sufrieron una drástica transformación debido a la imposición del sistema misional que avanzó por el territorio californiano desde su llegada por el mar del sur ${ }^{15}$ a finales del siglo XVII,

15 Después de varias expediciones fallidas, los frailes y soldados españoles irrumpieron en el escenario local por los mares colindantes al que hoy es conocido como puerto de La Paz. 
propiciando importantes procesos de cambio sociocultural como la sedentarización de los grupos cochimí y la imposición de la religión católica entre aquellos considerados como los pueblos más bárbaros que habían encontrado a lo largo de su andar por el nuevo continente. ${ }^{16}$

Mapa 3. Localización del pueblo cochimí

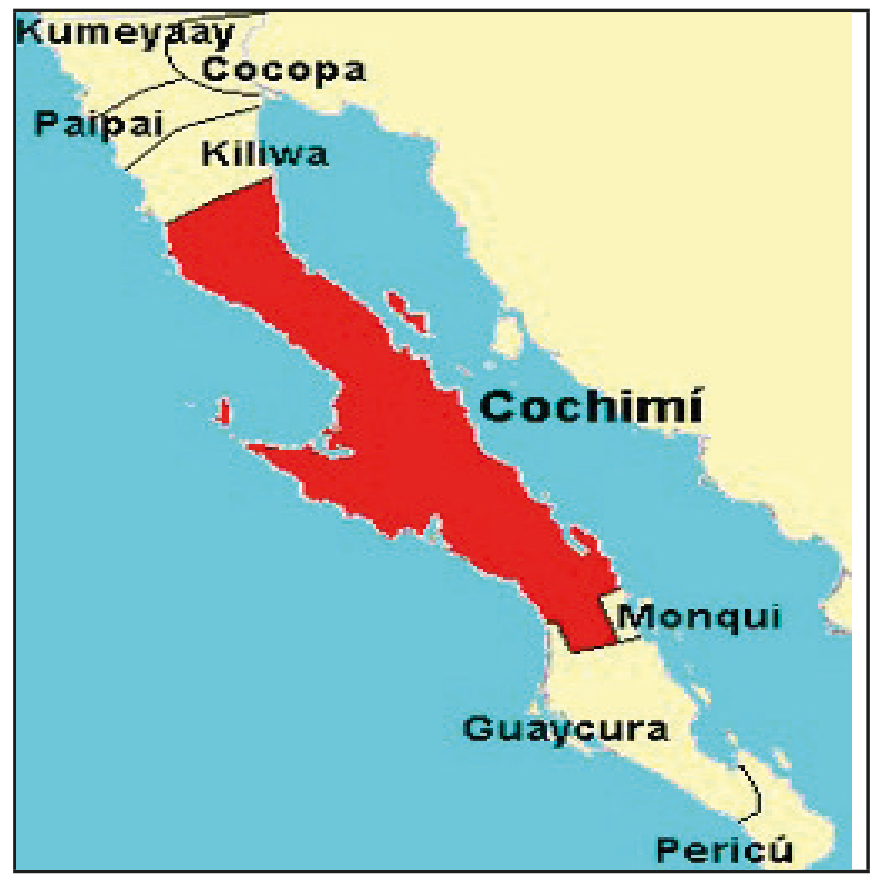

Fuente: Garduño, 2010.

De esta manera, el paso de las tres órdenes religiosas ${ }^{17}$ marcó un importante cambio en los grupos de la «nación cochimí», ${ }_{1}^{18}$ pues la evangelización incidió en la pérdida paulatina de la lengua y sus prácticas ancestrales se difuminaron en la nueva cultura a la par que las epidemias contagiadas por los extranjeros hacían

16 A su llegada a La Paz, los españoles se encontraron con los pueblos del sur y el desierto central, es decir, guaycura, cochimí, pericú, coras, monquis, entre otros, quienes tenían algunas prácticas que sorprendieron y horrorizaron a los extranjeros, como andar desnudos, practicar la poligamia o comer las semillas que defecaban. Una práctica conocida como la maroma consistía en comer un bocado amarrado a un hilo entre varias personas, quienes no lo masticaban sino solo lo introducían a través del lazo por su boca para saborearlo y, después, sacarlo y compartirlo con alguien más.

17 Jesuitas, franciscanos y dominicos.

18 Según Mario Magaña (2010) con nación los misioneros se referían a unidades culturales y lingüísticas, lo que en la actualidad denominamos como «pueblos indígenas». 
mella en la población nativa, lo cual provocó una fuerte debacle demográfica en este pueblo. Posteriormente, su cultura e identidad indígena se fueron reconfigurando frente a los dilemas planteados por los nuevos proyectos sociopolíticos, lo cual incidió en que fueran considerados extintos a principios del siglo XX. Quizá el último documento en el que se habla de los grupos cochimíes es el escrito en 1918 por David Goldbaum, quien con el objetivo de levantar un reporte demográfico para el gobierno del Distrito Norte de la Baja California hizo un recorrido por el desierto central y las ex misiones de Santa Gertrudis, San Borja y rancherías aledañas. En el informe titulado Noticia respecto a las comunidades indígenas que pueblan el Distrito Norte de la Baja California, detalla haber encontrado a cuarenta y ocho personas, veinte hombres, dieciséis mujeres y doce niños y niñas quienes se asumían como indígenas cochimíes, pero debido a que ya no hablaban la lengua y vestían como «rancheros mestizos», no consideró su filiación étnica ni su adscripción (Goldbaum, 1984). Después de su reporte es difícil encontrar más información sobre el pueblo cochimí pues con base en sus apreciaciones se afianzó el discurso sobre su extinción. Desde entonces, el silencio y el olvido se hicieron una constante para este pueblo que, aunque invisibilizado, mantuvo un lazo afectivo con su terruño, un sentido de pertenencia e identidad territorial lleno de recuerdos, emociones y significados que más adelante les dieron la fuerza suficiente para gritar: «¡Aquí estamos!» y organizarse para buscar apoyo y solucionar sus problemáticas agrarias en la comunidad de Santa Gertrudis, territorio que comenzó a ser objeto de disputa a raíz de la conformación del ejido Independencia, lo cual generó graves conflictos y tensiones dentro de este pequeño pueblo. ${ }^{19}$

A pesar de ser considerados oficialmente extintos, el ejido Independencia fue fundado en 1969 por treinta cochimíes, la mayoría pertenecientes a familias de la comunidad de Santa Gertrudis. Dentro de las 128040 hectáreas repartidas para este ejido, las cien que conforman la comunidad quedaron protegidas debido a

\footnotetext{
${ }^{19}$ Conformado en la actualidad por no más de cien personas quienes, en su mayoría, viven en la localidad de Guerrero Negro, a un par de horas de sus comunidades nativas -aún dentro del desierto central- que fue a donde migraron sobre todo a partir de 1954 cuando se fundó la empresa «Exportadora de Sal», lo que marcó el inicio de su incorporación al trabajo asalariado. No obstante su proceso de desterritorialización, es importante mencionar que mantienen un lazo afectivo con sus comunidades de origen ya que allí conservan sus casas, heredadas de sus padres o madres, y algunas familias aún conservan las antiguas huertas, ya sin la siembra de frutas u hortalizas pero llenas de recuerdos de su infancia; aunque en las comunidades viven muy pocas personas, las demás suelen ir constantemente, por lo menos en las celebraciones más relevantes como la Semana Santa y las fiestas patronales. Sobre ello ahondaré más adelante.
} 
su especificidad indígena y a la existencia de un monumento histórico: la misión de Santa Gertrudis la Magna, fundada en el sigloXVIII. No obstante, la aridez de las tierras del desierto central provocó que gran parte de las familias cochimíes comenzaran a salir pues, a pesar del reparto agrario, no obtuvieron el sustento necesario para permanecer en su comunidad de origen. Al respecto, Juana Villa platica que:

allá estábamos viviendo cuando se formó el ejido [en Santa Gertrudis] ya llevábamos dos hijos y cuando mi hijo cumplió seis años, mandamos al niño para que fuera a la escuela porque allá no había escuela [...] así que ya crecieron los plebes $^{20}$ y nos tuvimos que salir (Juana Villa, comunicación personal, agosto de 2016).

A partir de esto, los conflictos empezaron porque en la conformación del ejido una persona externa a la comunidad obtuvo dotación de tierras (debido a su matrimonio con una nativa) y dada la migración de los demás ejidatarios comenzó a apropiarse de sus derechos ya que en 1974, cuando se realizó el cambio de los representantes del Comisariado ejidal (en sus inicios conformado por personas de la comunidad), él logró posicionarse como el nuevo representante y paulatinamente fue depurando a la mayoría de las personas fundadoras, primero a cuatro en 1975 y, más adelante, en 1979, a la mayoría de ejidatarios cochimíes ${ }^{21}$ con el argumento de que habían abandonado las tierras y no las sembraban. ${ }^{22}$ Fue en esa época cuando la gente de este pueblo dio paso a los primeros intentos de organización para defender su terruño y comenzaron a relacionarse con algunas instancias gubernamentales como el recién creado Instituto Nacional Indigenista (INI). Desde entonces, una de las solicitudes a este instituto fue la realización de un estudio antropológico que les permitiera comprobar su antigüedad y legalidad en esas tierras, ${ }^{23}$ sin embargo no recibieron mucho apoyo y sus problemas en la comunidad se agudizaron años después, cuando la reforma al artículo 27 constitucional promovida por Carlos Salinas de Gortari en 1992 abrió el camino

\footnotetext{
20 Niños y niñas.

21 A la par, personas cercanas a él fueron incorporándose al ejido.

22 Al respecto, uno de los argumentos de las familias cochimíes es que a pesar de no vivir de planta en la comunidad, nunca dejaron de ir y de cumplir con sus responsabilidades, además de que las tierras ejidales son de agostadero, es decir, tierras de mala calidad destinadas para la ganadería, no para la siembra. Por otra parte, mencionan nunca haber sido notificados sobre el proceso de depuración.

23 El estudio antropológico se realizó del 2015 al 2017 por quien escribe este artículo gracias a una beca de maestría del CONACYT, en el Posgrado en Desarrollo Rural de la Universidad Autónoma Metropolitana-Xochimilco.
} 
al modelo neoliberal de libre mercado y estableció el fin del reparto de tierras, a la vez que reconocía personalidad jurídica a los ejidos y comunidades, con lo cual quitó el candado para la venta y la privatización. Debido a la reforma, a través del Programa de Certificación de Derechos Ejidales y Titulación de Solares Urbanos (PROCEDE) en 1993 se realizó una nueva acta del plano del ejido en el que no se registró ya a la comunidad, sino solamente la misión, así a raíz del PROCEDE se estableció que no existían huertos, casas, ni personas, a pesar de que para ese entonces vivían aún algunas familias en Santa Gertrudis.

De esa manera, las cien hectáreas de la comunidad que por su particularidad indígena se habían respetado en la conformación del ejido, fueron cedidas para usufructo de este y solo se registraron las dos hectáreas de la misión, pues es un monumento histórico y patrimonio arqueológico de Baja California. Con la modificación de los planos originales, el Comisariado ejidal pudo iniciar con el proceso de venta de 47 mil hectáreas colindantes con el Golfo de California, ${ }^{24}$ ya que debido a su cercanía con el también conocido como Mar de Cortés los terrenos costeros se volvieron de gran interés para algunos empresarios pues cuentan con una importante biodiversidad y playas de gran belleza como El Barril. Las y los cochimíes aún estaban en litigio por sus derechos agrarios cuando se realizó esta transacción, y a pesar de las irregularidades encontradas en los planos del PROCEDE así como en todo el proceso jurídico de depuración de sus derechos agrarios, ${ }^{25}$ la amenaza por parte del Comisariado ejidal de que en cualquier momento les prohibirán la entrada a la comunidad se agudizó, alegando que no poseen derechos agrarios y que la comunidad de Santa Gertrudis ya es parte, legalmente, del ejido.

Esta situación ha puesto en riesgo la permanencia de su comunidad de origen pero también reorganizó la defensa de su territorio a través de un notable e interesante proceso de revitalización cultural e identitaria pues si bien es cierto que hasta hace algunos años la identidad cochimí parecía estar en un periodo de silencio, en un tipo de identidad renunciada, o sea «una identidad latente a la cual se 'renuncia' tan solo como un método y en atención a una praxis dictada

\footnotetext{
24 «Solicitud de apoyo para la venta de las playas del ejido Independencia», 2007, en: Archivo Agrario, Carpeta Cochimí (CDI:s/f).

25 Aunque llevan más de 20 años en el proceso de recuperar sus derechos agrarios, desafortunadamente la mayoría de las familias ejidatarias no lo han logrado, a pesar de que han tenido apoyo de la CDI con presupuesto para la procuración de justicia, han tenido malas experiencias con los abogados que han conocido hasta ahora, además de que la corrupción ha sido también un duro enemigo a vencer.
} 
por las circunstancias, pero que en cualquier momento puede ser invocada o actualizada» (Erikson en Cardoso, 1992:64) es menester analizar cómo su identidad étnica reemergió a partir de que su territorio comenzó a ser objeto de disputa y confrontación con el Comisariado ejidal. Así, la identidad cochimí aparece como un valioso elemento organizador de la vida social al articular las fronteras entre los individuos, incidir en su reorganización como grupo social y fortalecer su sentido de pertenencia permitiéndoles crear una conexión simbólica con sus comunidades de origen con la cual pudieron delimitar sus fronteras y politizar su identidad colectiva través de la etnicidad, ya que como bien indica Cardoso de Oliveira, cuando los componentes subjetivos de la identidad étnica y su capacidad de convocatoria se llevan hacia un contexto de interacción-confrontación entre diferentes grupos culturales, la etnicidad se convierte en un elemento clave en las relaciones interétnicas (Cardoso, 1992).

En este sentido, como señala Miguel Bartolomé (1997), la identidad étnica debe ser analizada como un fenómeno procesual y cambiante, estrechamente ligado a contextos sociohistóricos específicos ya que, paradójicamente, la persistencia de estas identidades se muestra a través de las discontinuidades que llevan a los grupos étnicos a reelaborar la imagen que tienen de sí mismos. De este modo, es importante no asumir concepciones ahistóricas y esencialistas de las identidades étnicas -y de lo étnico- sino más bien reconocer su historicidad y el hecho de que constituyen solo una forma específica de las identidades sociales, sustancialmente distintas de otro tipo de identidades pero en permanente interconexión (Bartolomé, 1997). Por lo tanto, más que un atributo esencial o un conjunto de elementos materiales, las identidades étnicas son construcciones procesuales, relacionales y ligadas a contextos sociohistóricos particulares que constituyen la forma en que una colectividad se asume frente a otras y en relación a sí misma, siendo una construcción que sirve a los grupos étnicos para distinguirse de los «blancos» o mestizos a partir de una confrontación con sus propios modelos societales (Bartolomé, 1997).

No obstante, si bien los límites étnicos son los que definen a un grupo (Barth, 1976), es importante atender la estrecha relación que guardan las categorías de cultura e identidad, pues la cultura entendida como un marco de prácticas, símbolos, valores, usos y costumbres que configuran la vida de los grupos dentro de la sociedad en la que se desarrollan, brinda marcos de referencia con los cuales identificarse y delimitar sus fronteras frente a otras y otros a través de lo que Miguel Bartolomé define como las bases culturales de la identidad, es decir, 
componentes de la cultura relevantes para los grupos étnicos como la lengua, la historia, la adscripción parental y el territorio (Bartolomé, 1997:78). Así, además de la pérdida de sus derechos agrarios, la recuperación de algunos de estos componentes fue lo que condujo a las y los cochimí a revalorarse como tal e iniciar un significativo proceso de revitalización cultural a través de la asociación Milapá.

\section{La asociación Milapá y la revalorización propia}

La tierra llama, la tierra mueve, la tierra lleva a organizarse. Después de confirmar que su pequeño territorio gertrudino era amenazado, la pregunta «¿qué hacemos?» se volvió definitiva y la acción más urgente ante la injusticia, las amenazas y la impotencia, por lo tanto decidieron organizarse para defender su comunidad a través de la asociación Milapá, ${ }^{26}$ constituida legalmente en octubre del 2008 con la finalidad de buscar apoyo para la recuperación de sus derechos agrarios, pero también para ser reconocidos como un pueblo vivo de Baja California y dejar de ser vistos como un remedo del pasado, como un pueblo extinto. Al respecto, Francisco Grado, uno de los fundadores, menciona:

algo que nos motiva es que nos reconozcan, porque mucha gente nos decía: "¡Qué cochimís van a ser ustedes!, tú para empezar no tienes ni el color" porque luego luego se van por el color de la piel y por la fisionomía, ya tenemos los estereotipos de lo que debe ser un indígena [...] y que se nos reconozca primeramente, que aunque no somos con las características que nos han metido en la cabeza que así debemos de ser los indios, no las tenemos, pero tenemos el orgullo por la tierra, el corazón, el alma de ser descendientes de una tribu. Dicen que estamos extintos, pero estamos nosotros aquí, entonces no estamos extintos. Somos parte de ellos y aquí estamos, están extintas las características y las cosas que se tenían de los indios, pero nosotros seguimos, no con taparrabos ni con huaraches ni descalzos ni cosas así, pero seguimos siendo nosotros (Francisco Grado, comunicación personal, agosto de 2016).

\footnotetext{
${ }^{26}$ Así se referían las y los antiguos habitantes del desierto central a un cactus característico de la zona. A su llegada, los españoles figuraron al árbol como un cirio, como una vela, por lo que lo nombraron de esa manera; aunque en realidad es difícil precisar qué significa Milapá en lengua cochimí, solo se sabe que de esa manera se referían a esta planta en particular.
} 
Al momento de constituirse la asociación reunió a 85 personas quienes se identificaban como descendientes cochimíes de Santa Gertrudis, San Borja y algunas rancherías aledañas como San Regis, las tres comunidades pertenecientes al desierto central. El trabajo realizado hasta la fecha se ha centrado en la recuperación de sus derechos agrarios, en la exigencia de su reconocimiento como indígenas y en el «rescate» de algunos elementos de su cultura ancestral, como la lengua, aunque debido a que esta sí se extinguió durante el siglo XIX no existe ningún hablante en la actualidad y son pocos los registros que existen de la subfamilia lingüística a la que pertenecían las variantes dialectales que se hablaban en el desierto central, lo que ha dificultado dicha empresa. ${ }^{27}$ No obstante, a lo largo de diez años han conseguido uno de sus objetivos: ser reconocidos de forma oficial como indígenas a través de cartas de adscripción emitidas por la Comisión Nacional para el Desarrollo de los Pueblos Indígenas y su inclusión en el Censo de Población y Vivienda 2010 del Instituto Nacional de Estadística y Geografía, ${ }^{28}$ así como por los demás pueblos indígenas de la península, colocando de nuevo en el mapa de los grupos nativos de Baja California al pueblo cochimí. Chatita Ramos, una de las primeras defensoras de su comunidad, narra sobre el comienzo del proceso:

eso de la [sic] Milapá, pues empezamos a hacer plática qué podíamos hacer por la cuestión de las tierras, a dónde deberíamos de ir y no dejarnos vencer, luchar por lo que es nuestro porque son cosas que son de la comunidad, muy antiguas pero de ahí salimos nosotros; nosotros no somos extranjeros, somos de ahí y amamos la tierra y amamos todo lo que ahí se da, nos gusta y no nos gusta que otro vaya a meterse ahí nada más porque "ay qué bonito aquí", no, que lo respeten [...] Luego se hizo el comité y ya se hicieron juntas, se hicieron asambleas, se juntaron, la comunidad luego se registró en el INEGI allá en el CDI, nos dijeron a nosotros que para poder entrar a ser más respetados teníamos que completar 51 personas que fueran de ahí, no importaba que fueran recién nacidos pero que tenía que ser el grupo de 51 personas para que ya quedáramos en el INEGI como

\footnotetext{
27 Según León Portilla: «Cada una de estas subfamilias comprendía distintos grupos étnicos que desarrollaron sus respectivas lenguas, las cuales son reconocidas en la actualidad por la forma en que los misioneros las identificaban; en el caso de los cochimí, por ejemplo, las denominaciones de sus lenguas estaban en función de los nombres de las misiones más cercanas al grupo, de ahí que existan el grupo javiereño, el cadegomeño, el de comondú, el de Santa Gertrudis, el borjeño, el didiu, el mongui, el ignacieño y el laymón» (León Portilla, 1983:42).

28 El cual registró 85 personas que se autoadscriben al grupo indígena cochimí en el municipio de Ensenada, con la clave 1502 (INEGI, 2010).
} 
reconocida la comunidad de Santa Gertrudis y así fue que se completaron, hasta sobraron un montón (Gertrudis Ramos, comunicación personal, abril de 2016).

Para Luz Villa, el amor por su tierra, el ser nativa, en contraste con las personas del Comisariado ejidal que no lo son y que tampoco tienen una historicidad como la suya, fue lo que la llevó a organizarse en la asociación Milapá:

la tierra jala, tanto así que yo no me puedo ir a otra parte porque yo prefiero morir en Santa Gertrudis, prefiero quedarme para siempre ahí hasta que Diosito lo quiera y dejarle a mis hijos esa tierrita que nos la dejó nuestro padre, es nuestra tierra que nos vio nacer, es la tierra en donde vivieron nuestros antepasados, es la tierra en sí que lo jala a uno, la pertenencia de saber de dónde es uno, saber que de allí soy [...]. Yo siento que eso fue el coraje que tuve y se me dio la oportunidad cuando se formó Milapá y le entré con todas las ganas porque yo tenía ese sentir desde niña que me han dado Dios y mis antepasados [...] esto viene de fondo y yo por eso lo hice, por eso estoy en Milapá (Luz Villa, comunicación personal, abril de 2016).

Como se puede observar en estos testimonios, el territorio fue clave para la revitalización cultural e identitaria pues además de ser un espacio apropiado por los grupos para la satisfacción de sus necesidades vitales, tanto materiales como simbólicas, es también un lugar de apego ya que las relaciones que se crean en él generan lealtades y afectividades que coadyuvan a configurar las identidades, pues se construyen dentro de marcos sociales y espaciales específicos a través de los cuales las personas establecen importantes vínculos con sus territorios reforzando sus lazos de lealtad y su sentido de pertenencia (Zambrano, 2006). Si bien los conceptos de sentido de pertenencia e identidad no son términos análogos, se complementan, ya que «la pertenencia brinda un sentimiento de seguridad personal y una fuerza cohesiva a los grupos, y por ello, permite contar con un entorno estable para desplegar los proyectos de vida» (Hopenhayn y Sojo, 2011:153). Entonces, el sentido de pertenencia entendido como un elemento de la subjetividad compuesto por percepciones, valoraciones y disposiciones, permite ver las adscripciones identitarias como derivación de procesos territoriales e históricos concretos, más que como marcadores irreductibles (Bello, 2016). Sin embargo, aunque el sentido de pertenencia socioterritorial es parte de la identidad, la trasciende, pues a pesar de los cambios en los límites y en las fronteras establecidas entre los grupos, la pertenencia territorial puede persistir aun en procesos de desterritorialización como la migración, los éxodos o las diásporas 
ya que está enraizada subjetiva y simbólicamente en la memoria de las personas y de las colectividades (Giménez, 2001). Y es que sin duda, una de las características importantes de las identidades étnicas es su contenido emocional dado que la afectividad es un componente subjetivo relevante que establece lazos de lealtad y pertenencia, pues como bien indica Miguel Bartolomé: «la capacidad de convocatoria de la identidad se deriva precisamente de ese contenido afectivo, derivado de la participación en un universo moral, ético y de representaciones comunes, que la hace comportarse como una lealtad primordial y totalizadora» (Bartolomé,1997:48-50). Estos lazos contenidos por un conjunto de afinidades permiten a los pueblos reforzar los límites de su identidad pues esta no solo se enmarca en espacios geográficos, sino también en las emociones y en los afectos (Giménez, 2001).

Sin duda, en la actualidad la pertenencia territorial es uno de los componentes de su identidad y el motivo de la reemergencia de esta pues como bien apunta Roberto Cardoso (1992), para que un grupo étnico pueda persistir es indispensable un territorio que asegure la actualización de su forma de organización típica. No obstante, hemos visto que dicha organización no está basada solamente en el enfoque utilitario del territorio sino en las relaciones simbólicas y afectivas que las personas establecen con él. De tal forma, considero que el sentido de pertenencia cochimí es uno de los elementos que permite explicar la persistencia de su identificación étnica a pesar de la disgregación y aunque, al parecer, no existan en ellos y ellas rasgos diferenciales manifiestos (Cardoso, 1992).

Por consiguiente, la organización de descendientes cochimí en la asociación Milapá muestra cómo a pesar de los procesos de transformación cultural o dispersión socioterritorial, los vínculos y afectos por el territorio les permitieron continuar «habitándolo» a través del sentido de pertenencia, e impulsaron la organización para defenderlo, fortaleciendo su cultura y memoria colectiva, algo de gran trascendencia sobre todo en pueblos en riesgo como los yumanos y, en específico, para el pequeño pueblo cochimí. En este proceso la pertenencia territorial ha tenido mucho peso, pues a pesar de los cambios socioculturales y de la desterritorialización mantuvieron fuertes lazos con su terruño, con sus recuerdos, con sus ancestros, con su santa, además de algunas prácticas culturales que han definido su identidad y que les permite diferenciarse de los demás grupos indígenas de la región y del país. De este modo y aunque los ciclos migratorios les alejaron físicamente de su comunidad de origen, el territorio como un contenedor de afinidades, situaciones y experiencias les permitió mantener y 
reforzar sus límites físicos brindándoles un «estatus» de pertenencia a un grupo social partiendo del sentido territorial pues «la dimensión territorial caracteriza de modo relevante la estructura misma de la colectividad y de los papeles asumidos por los actores» (Giménez, 2001:8). De esta forma, mantuvieron una relación afectiva con la comunidad de Santa Gertrudis y con su territorio más amplio: el desierto central; y ante la disputa por su comunidad fortalecieron su identidad étnica como una estrategia de defensa de su terruño en peligro, revalorizando su ascendencia e identidad étnica.

\section{Algunas reflexiones para concluir}

Como se puede observar en el caso del pueblo cochimí, las identidades con un fuerte contenido simbólico, afectivo y territorial nos permiten analizar cómo la modificación de algunos elementos culturales o la desterritorialización de un pueblo no suponen, necesariamente, la renuncia de su identidad pues aun los grupos que han sufrido fuertes procesos de transformación y disgregación pueden seguir definiéndose en términos étnicos «aunque estos ya no remitan a una tradición específica» dado que «las configuraciones identitarias se pueden basar en una filiación cultural propia, o asumida como propia, con independencia de que la tradición cultural vaya cambiando con el transcurso del tiempo» (Bartolomé, 1997:75). De este modo, la transformación cultural puede considerarse como una expresión alterna y estratégica que los grupos utilizan para persistir a pesar de los cambios y están ligados a los procesos de re-existencia, es decir, a la reinvención que los grupos hacen de sus culturas e identidades con la finalidad de reafirmar su existencia cultural, no en un sentido de una falsa construcción sino de crearse y recrearse a través del tiempo (Zambrano, 2006).

A pesar de las transformaciones culturales y la fragmentación territorial, el proceso de este pueblo muestra la relevancia de los afectos por el territorio y su fortaleza como emblemas en la reconfiguración de la memoria y la identidad colectiva, pues gracias a estos vínculos afectivos su adscripción étnica tomó un nuevo impulso convirtiéndose en un importante referente en momentos de confrontación lo cual muestra también la vitalidad y el dinamismo de las culturas e identidades, así como el sobresaliente papel de los sujetos en la construcción de su devenir. De esta manera, se puede inferir que la dimensión política de su 
identidad, es decir, la etnicidad, emergió en medio de la disputa por el territorio y configuró un proyecto colectivo de reconocimiento a su cultura, apelando a su «expresión ideológica contrastativa» (Cardoso, 1992) para diferenciarse de quienes intentaban apropiarse de sus derechos agrarios, sobresale aquí la dimensión política de su identidad ya que, como bien afirma Miguel Bartolomé (1997), esta expresión supone la afirmación de lo propio en confrontación con lo alterno y presenta a la etnicidad como una afirmación protagónica de una identidad específica. Asimismo, lo anterior demuestra cómo la identidad étnica vista como un valor en cuanto categoría ideológicamente valorizada (Cardoso,1992) puede ser tomada como alternativa en situaciones de confrontación, lo que nos remite al valor transaccional de la identidad y a la voluntad de los individuos para diferenciarse socialmente ya que esta puede ser una elección y convertirse en un medio para organizar el sentido de la acción social, pero también devela a la etnicidad como un fenómeno político y simbólico, como una construcción ideológica de la identidad en la que las diferencias culturales asumen propósitos políticos frente a otros grupos de un sistema social, es decir, como expresión de determinadas relaciones interétnicas (Cardoso, 1992).

La lucha del pueblo cochimí nos recuerda que así como las culturas son diversas, lo son también las resistencias y en los pueblos nativos bajacalifornianos podemos ver no solo otras formas de organización sociocultural sino otras estrategias de defender lo propio partiendo de sus especificidades históricas, geográficas y culturales así como de sus problemáticas, y aunque la resistencia de estos pueblos no va en contra de los megaproyectos que asechan su territorio sino hacia la invasión que han vivido por parte de agentes externos, es menester entender que esto no es fortuito, por el contrario, responde a sus características y procesos culturales e históricos pero, sobre todo, a lo que las personas consideran como un problema y como prioridad. Para entender estas diferencias, es necesario partir de una mirada más amplia que considere las particularidades de estos grupos, pues si bien es cierto que en los pueblos de Baja California es difícil promover procesos comunitarios, ello no quiere decir que no respondan, desde sus especificidades y necesidades, a los problemas y conflictos que les aquejan, como las invasiones a sus territorios y la pérdida de algunos elementos culturales.

De esta manera, los pueblos de Aridoamérica (Kirchhoff, 1960) representan grandes retos para quienes nos dedicamos a colaborar con los pueblos o movimientos, convocándonos tácitamente a entender a profundidad las singularidades de cada pueblo, de cada proceso y de cada territorio así como respetarlas, para entonces encontrar la manera de aportar a sus organizaciones pues en un 
país como México, muchas son las realidades y vastas también las formas de respuesta. Precisamente, mi tiempo de acompañamiento al pueblo cochimí en su proceso de revitalización cultural ha implicado la revalorización de todas las luchas, desde las magnánimas anticapitalistas hasta las pequeñas y personales, pues una de las enseñanzas de la gente de este pueblo es que todos los esfuerzos son válidos cuando se trata de defender el terruño y la permanencia en él. Y es que en pueblos a los que tanto les ha costado persistir, revitalizar la cultura y la identidad se convierte en una necesidad urgente y también en una digna trinchera desde la cual organizarse para defender no solo el territorio, sino la existencia misma. Así pues ¡qué vivan -y sigan- las diversas resistencias!

\section{Bibliografia citada}

Álvarez de Williams, Anita. (1975). Primeros pobladores de la Baja California: Introducción a la antropología de la península. Mexicali, B. C.: Gobierno del Estado de Baja California, $1^{\text {a }}$. edición.

Aschmann, Homer. (1959). The central desert of Baja California: Demography and Ecology. Iberoamericana, vol. 42. Berkeley y Los Ángeles: University of California Press.

Barth, Frederik. (1976). Los grupos étnicos y sus fronteras. México: Fondo de Cultura Económica.

Bartolomé, Miguel. (1997). Gente de costumbre y gente de razón. Las identidades étnicas en México. México: Siglo XXI editores.

Bendímez-Patterson, Julia. (1987). Antecedentes históricos de los indígenas de Baja California. Estudios fronterizos, V (14), septiembre-diciembre, pp. 11-46.

Bravo Espinoza, Yacotzin. (2018). Los territorios indígenas y la colonialidad del derecho: la lucha por la defensa del territorio indígena Cucapá (Baja California, México). Revista TEFROS, 16 (1), enero-junio, pp.34-68.

Bello, Álvaro. (2016). ¿Pertenencia o identidad? Implicancias de dos categorías socioculturales para los derechos indígenas y la lucha contra el racismo. Revista Antropologías del Sur, 3 (6), pp. 13-27.

Cardoso de Oliveira, Roberto. (1992). Etnicidad y estructura social. México: Centro de Investigaciones y Estudios Superiores en Antropología Social.

Garduño, Everardo. (1994). En donde se mete el sol. Historia y situación actual de los indígenas montañeses de Baja California. México: Consejo Nacional para la Cultura y las Artes-Dirección General de Culturas Populares.

Garduño, Everardo. (2010). Los grupos yumanos de Baja California: ¿indios de paz o indios de guerra? Una aproximación desde la teoría de la resistencia pasiva. Estudios fronterizos, 11 (22), pp.185-205. 
Garduño, Everardo. (2011). De comunidades inventadas a comunidades imaginadas y comunidades invisibles. Movilidad, redes sociales y etnicidad entre los grupos indígenas de Baja California. México: Universidad Autónoma de Baja California/Comisión Nacional para el Desarrollo de los Pueblos Indígenas.

Giménez, Gilberto. (2001). Cultura, territorio y migraciones. Aproximaciones teóricas. Alteridades, 11(22), julio-diciembre, pp. 5-14.

Goldbaum, David. (1984). Noticia respecto a las comunidades indígenas que pueblan el Distrito Norte de la Baja California. Revista Calafia, V (3), pp. 19-25.

Hopenhayn, Martín y Ana Sojo. (2011). Sentido de pertenencia en sociedades fragmentadas: América Latina en una perspectiva global. Buenos Aires: Siglo XXI Editores.

Instituto Nacional de Geografía y Estadística (INEGI). (2010). Censo de Población y Vivienda 2010. México: Instituto Nacional de Geografía y Estadística.

Kirchhoff, Paul. (1960). Mesoamérica, sus límites geográficos, composición étnica y caracteres culturales, Revista Tlatoani, (3).

Kouri, Emilio. (2015). La invención del ejido. Nexos, 37, enero, pp. 54-56.

León Portilla, Miguel. (1983). Los primeros californios: pre-historia y etnohistoria. Panorama histórico de Baja California. Mexicali: Universidad Nacional Autónoma de México/UABC.

Magaña, Mario. (2010). Indios, soldados y rancheros. Poblamiento, memoria e identidades en el área central de las Californias (1769-1870). La Paz, B.C.S.: Gobierno del Estado de Baja California Sur/Instituto Sudcaliforniano de Cultura/El Colegio de Michoacán/ CONACULTA.

Massey, William. (1949). Tribes and languages of Baja California. Southwestern Journal of Antropology, 5 (3), pp. 272-307.

Mathes, Michael. (1974). Californiana III. Documentos para la historia de la transformación colonizadora de California (1679-1686). Madrid: José Porrúa Turanzas.

Meigs. Peveril. (1939). The kiliwas indians of Lower California. Berkeley, California: University Press.

Michelsen, Ralph. (1991). La territorialidad del indígena americano de la tierra alta del norte de la Baja California. Estudios fronterizos, 24-25, enero-abril-mayo-agosto, pp. 151-160, doi: 10.21670/ref.1991.24-25.a06

Mixco, Mauricio. (1978). Cochimí and Proto-Yuman: Lexical and Syntactic Evidence for a New Language Family in Lower California. University of Utah Anthropological Papers, (101).

Morales, Ana Paola. (2016). Cochimíes, indios del norte. Etnohistoria y Patrimonio Cultural del Desierto Central de Baja California. Siglo XVIII al presente. Tesis de maestría inédita. México: El Colegio de la Frontera Norte, A.C.

Ochoa, Jesús. (1979). Distribución actual de los grupos indígenas de Baja California. Calafia, 4 (1), pp. 10-18.

Uriarte, María Teresa. (2013). Historia y Arte de la Baja California. México: Instituto de Investigaciones Históricas-UNAM/Instituto Sudcaliforniano de Cultura.

Zambrano, Carlos. (2006). Territorios plurales, cambio sociopolítico y gobernabilidad cultural, en Carlos Zambrano (autor), Ejes políticos de la diversidad cultural. Colombia: Siglo del Hombre Editores: Universidad Nacional de Colombia. 


\section{Archivos}

Archivo Agrario de la Comisión Nacional para el Desarrollo de los Pueblos Indígenas, Carpeta Cochimí, Ensenada, Baja California

INEGI. (2010). Censo de Población y Vivienda. México: Instituto Instituto Nacional de Geografía y Estadística.

\section{Cómo citar este artículo:}

Velasco Pegueros, B. Alejandra. (2020). Otras formas de defender el territorio: la revitalización cultural e identitaria del pueblo cochimí de Baja California. Revista Pueblos y fronteras digital. 15, pp. 1-26, doi: 10.22201/cimsur.18704115e.2020.v15.443 